\title{
Analysis and Comparison of Factors Influencing University Choice
}

\author{
Navrátilová Terez̧a
}

\begin{abstract}
This study applies the theory of planned behaviour to a university's selection process. Within the structural equation modelling a measurement model is defined for two types of universities - economic and technical. Furthermore, it is examined whether the designed manifest variables determine the latent variables featured in the theory of planned behaviour, namely the attitudes toward the behaviour, subjective norm, and perceived behavioural control. Based on the values of standardized regression coefficients for each of the factors, comparison between the students of economic and technical faculties was carried out.
\end{abstract}

Keywords: theory of planned behaviour, structural equation modelling, university choice

\section{INTRODUCTION}

Selecting university is a decision-making process, which could be included in a field of so-called career decision-making. According to Gati and Asher (2001), this term refers to a process that is undertaken by an individual, who is considering pursuable career alternatives, compares them, and then selects one. The choice of university education and the topic of career are closely related to each other and according to Germeijs et al. (2012) it creates a "mini-cycle", which is a part of the whole career development cycle. As well as other decisions that may have long-term consequences on the life of an individual, this kind of decision is also influenced by number of factors.

In the first place it can be assumed that there could be different motivation factors, which accompany the decision-making process regarding university selection, due to the fact that applicants have different expectations and perceptions of the university degree benefits. The decision-making process is also affected by various reference groups whose opinions are more or less important to the individual. It also involves situations when different limiting factors can play their role in such process and could be taken into individual's consideration and therefore influence the intention to choose or reject specific university. Knowledge of such information is hence significant for the management of universities, as they can prepare the right marketing strategy aiming at specific target audience, based on these facts.

The aim of this paper is to analyze the factors that may influence the decision-making process regarding the choice of university and compare whether the influence is different in cases of applicants for economic education and applicants for technical education.

\section{THEORETICAL BACKGROUND}

The theory of career decision-making is based on the general decision-making models. Those are according to Gati and Gal (2008) applicable to situations that are typical for having: 

a) an individual who has to implement a decision,
b) goal or goals that the individual wants to achieve,
c) alternatives the individual will choose from,
d) factors the individuals will have to bear in mind when comparing the alternatives,
e) necessity to collect and process information (often under conditions of uncertainty).

For career decision-making is typical that the number of alternatives the individual must choose from is as large as the number of information sources that can be used. On the top of that there are many criteria to be evaluated and the final decision is also influenced by so-called the significant others such as parents or friends (Gati, Asher, 2001).

In connection to this process the carrier indecision is examined together with the factors that cause it. Three groups of problems are most often stated regarding the career decision-making process (Gati, Saka, 2001). It is above all - the lack of willingness to implement the decision, either based on lack of motivation or on irrational expectations. Another group of problems comes from the lack of information regarding the decision-making process itself or possible alternatives or even the available sources of information. The third group includes problems that relates to information inconsistency.

Many researches in the field of career decision-making examine the influence of individual factors or respectively the influence of other people individually (e.g. Pappas a Kounenou, 2011) or rather focus on the way the decisions are made (e.g. Gati et al., 2010; Germeijs et al., 2012; Galotti et al., 2006).

The theory of planned behaviour on the process of career decision-making is applied in this study. This theory is used to understand, anticipate and simulate the human behaviour in different situations (Ajzen, 2012).

Theory of planned behaviour was expanded and extended by Icek Ajzen on the basis of the earlier theory of reasoned action. Whilst the theory of reasoned action used only two variables that influence human behaviour, specifically the attitudes toward the behaviour and subjective norm, the new theory of planned behaviour adds the concept of perceived behavioural control (Ajzen, 2008). These variables have according to the theory of planned behaviour consequent impact on behaviour intention, which further indicates the actual behaviour. These three variables can be measured directly, i.e. we can ask about them, or indirectly, when we examine individual elements of these factors and the strength of their influence. We then evaluate three groups of expectations (opinions) that correspond with these variables (see Fig 1). By the use of indirect measuring it is possible to study the influence of these expectations and therefore raise the predicative ability of the tested construct.

Behavioural beliefs include both; beliefs about what the probability of possible consequences of particular behaviour is as well as an evaluation of whether these behavioural consequences are positive or negative for that very individual.

Normative beliefs are determined by what the expectations of others, i.e. reference groups concerning the particular behavioural are, and to what extend is the individual willing to fulfill these expectations, therefore what is the significance of such expectances to the individual.

Control beliefs as indicators of perceived behavioural control were in the theory of planned behaviour included for the following reason. The previous theory of reasoned action was unable 
to explain situations when the behaviour of the individual depends on external factors, i.e. it is not fully under his control. In such cases, the individual may have an intention to implement certain behaviour, but for some reason he does not have sufficient possibilities or abilities to do so. These factors then restrain (or facilitate) the implementation of that behaviour. The model in this section addresses both; existence of such factors and control that the individual subjectively assigns them.

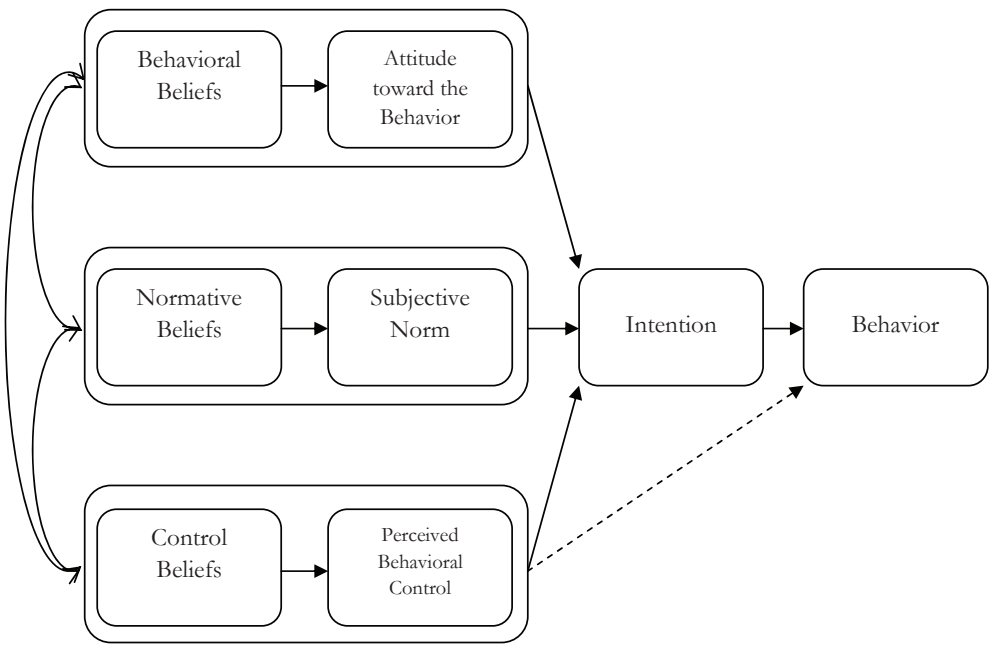

Fig. 1 - Theory of planned behaviuor. Source: Ajzen (2008), p. 538.

Attitudes toward the behaviour, subjective norm and perceived behavioural control are usually mutually correlated and subsequently form the behavioral intention. According to Ajzen (2002) it is true that the more favorable the attitude and subjective norm and the higher perceived control, the stronger the intention to implement such behaviour. Perceived behavioural control may also influence behaviour directly by the means of so-called actual control (Ajzen, 2008) in form of limitation in terms of insufficient opportunities or sources, which are necessary to implement the behaviour.

Theory of planned behaviour is applied in many scientific fields, from medicine and sociology to consumer behaviour. It is mainly because it allows analyzing the influence of intention on behaviour in various contexts. In the field of career decision-making Arnold et al. (2006) studied the influence of those three main variables from the theory of planned behaviour on the intention of choosing specific profession and they came to confirmation of these relations. This paper applies the abovementioned theory on behaviour analyzing university selection, because with this kind of behaviour all three factors can be assumed relevant; namely the influence of personal attitudes of candidates in decision-making process (attitudes toward the behaviour) together with the influence of reference groups (subjective norm), and least but not last with the existence of certain restrictive factors (perceived behavioural control). 


\section{RESEARCH OBJECTIVE AND METHODOLOGY}

\subsection{Entry data}

There has not been any similar research carried out within the Czech Republic yet. Even though university students (or graduates) are subject to a number of researches, the issue of career decision-making process has not been addressed yet or perhaps just marginally. The only exception is the publication "How the pupils of elementary and secondary schools choose their further education and/or professional career" (Št’astnová, Drahoňovská, 2012) which only states the relative response rates and there is not any dependence examined in detail.

To achieve the set aim, i.e. the analysis of factors that may have an influence on the decisionmaking process regarding the university choice, and their comparison in case of applicants for university education of economic or technical type; data obtained by questionnaire filled in by first year university students of both fields were used. Students of two VŠB-Technical University of Ostrava faculties - in particular Faculty of Economics and Faculty of Mechanical Engineering served as a population for the research.

This basic group was in case of Faculty of Economics a quota sample according to the study program, respectively study field and its size was 278 students; in case of Faculty of Mechanical Engineering the technique of suitable opportunity was used and the group had only 75 students due to low response rate.

The questionnaire served as a tool for data collection and it was created on the basis of the theory of planned behaviour, whereas indirect way of measuring the latent variable of attitudes toward the behaviour, subjective norm and perceived behaviour control was applied. These variables were therefore examined founded on the relevant ideas, as described in the previous chapter.

\subsection{Structural equation modelling}

To analyze the collected data, method of structural equation modelling was used (furthermore SEM), through which the theory of planned behaviour model validation was verified. Such modelling allows examining the relations between the variables that can be either observed (manifest, direct measured) or latent (hidden), whereas each latent variable is usually captured by several observed ones. Besides these two types of variables there can also be a residual variable, indicating the measurement or estimate error (Urbánek, 2000). The general structural model has two parts. It consists of both the measurement model as well as the model of latent variables (Nachtigall, 2003).

Relationships between manifest variables are part of the measurement model. These variables can constitute latent variable either by equally corresponding with each other (i.e. one latent variable equals one manifest variable) creating so-called substitute variable, or one latent variable measured by several manifest variables in which case we refer to the so-called indicators. According to Urbánek (2000) the observed variables in the measurement model correlate only with measured latent variable, therefore "all variance explained by linear relationship of observed variable on latent variable represents all "valuable" variance of observed variable" (Urbánek, 2000 , p. 67). Part of the variance that cannot be explained is so-called residual variance, and is considered as latent variable. Algebraically, the measurement model is formulated by the system of two equations in matrix form 
$\mathrm{x}=\Lambda_{\mathrm{x}} \zeta+\delta$

$\mathrm{y}=\Lambda_{\mathrm{y}} \eta+\varepsilon$,

where $x$ represents the indicator for latent variable $\zeta, y$ for latent variable $\eta$, $\zeta$ is the latent exogenous variable, $\eta$ is latent endogenous variable, $\Lambda_{\mathrm{x}}$ and $\Lambda_{\mathrm{y}}$ are matrix of structural coefficients for relationships between the variables $x$ and $\zeta$ and variables $y$ and $\eta, \delta$ and $\varepsilon$ are residual variables for $x$ and $y$. In addition to these elements also covariance matrix of residual variables $\Theta_{\delta}$ a $\Theta_{\varepsilon}$ are part of the measurement model. Those are usually diagonal, and thus do not correlate with each other within the model.

Model of latent variables captures relationships between latent variables, respectively which latent variable is independent (exogenous), and is therefore not influenced by any other independent variable in the model, and which latent variable is dependent (endogenous) and is therefore influenced by other variables in the model. Equation for the latent variable model is

$\eta=\mathrm{B} \eta+\Gamma \xi+\zeta$

where in addition to the above variables also figure the structural coefficients matrixes of latent endogenous, respectively exogenous variables $B$ and $\Gamma$, disturbance $\zeta$ as well as covariance matrix of latent exogenous variables $\Phi$ and covariance matrix of disturbances $\Psi$.

\section{MEASUREMENT MODEL RESULTS}

In this part the measurement model those three latent variables derived from the theory of planned behaviour are examined in application on behaviour when selecting the university. This model is analyzed separately for the sample of students of economics and separately for the sample of students of mechanical engineering.

Characteristics of tested model:

- Total number of variables: 29

- Number of observed variables: 13

- Number of latent variables: 16, out of which number of residual variables:13

Description of individual variables is stated in Tab. 1 and further in text.

Tab. 1 - Variables in measurement model. Source: own processing.

\begin{tabular}{|l|l|l|}
\hline Variable type & $\begin{array}{l}\text { Variable } \\
\text { sign }\end{array}$ & $\begin{array}{l}\text { Variable name in the theory of } \\
\text { planned behavior }\end{array}$ \\
\hline \multirow{4}{*}{ observed } & b1-b6 & behavioural beliefs \\
\cline { 2 - 3 } & s1-s3 & normative beliefs \\
\cline { 2 - 3 } & c1-c4 & control beliefs \\
\hline \multirow{3}{*}{ latent } & ATT & attitudes toward the behaviour \\
\cline { 2 - 3 } & SN & subjective norm \\
\cline { 2 - 3 } & PBC & perceived behavioural control \\
\hline residual & e1-e13 & \\
\hline
\end{tabular}


The latent variable „attitudes toward the behaviour” (ATT) is measured by the means of observed variables b1-b6 that correspond with the respondents' opinions regarding the issue of what benefits can the correct university selection bring along as well as what is the probability of achieving these benefits by selecting the right university. In particular it concerns the following benefits:

b1 developing study skills and abilities,

b2 gaining deeper knowledge and information in a particular field,

b3 promising career prospects,

b4 satisfying society status,

b5 success in professional career,

b6 high standard of living.

The latent variable "subjective norm" (SN) is measured by observed variables s1-s3 which evaluate the influence of three reference groups on the respondent and opinions of these groups on importance of correct choice of university. The variable s1 indicates the influence of parents, s2 closest friends and s3 classmates.

The latent variable "perceived behavioural control" (PBC) is measured by the use of observed variables c1-c4 that reflect what factors could have limiting influence on the choice of the right university and the intensity of their impact on the individual. More specifically it includes the following factors:

c1 lack of information during the decision-making process,

c2 economic resources,

c3 ability to identify own interests, needs and wishes,

c4 personal skills, abilities and talents.

\subsection{Factors influencing the choice of economic type of university}

The following figures demonstrate relationships between individual variables of the measurement model and the values of standardized regression coefficients. The recommended value for standardized regression coefficients that express the strength of relationship between variables corresponding to the latent variables is at least 0.5, optimally 0.7 (Hair et al., 2010). 


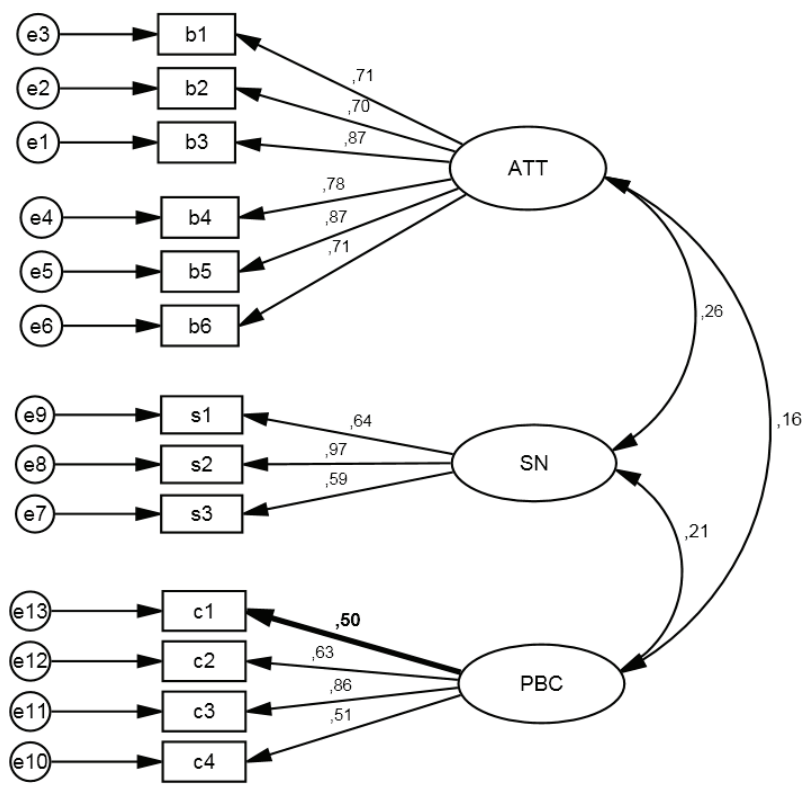

Fig. 2 - Regression coefficients of measurement model - Faculty of economics students. Source: own processing.

In case of respondents from the faculty of economics the latent variable "attitudes toward the behaviour" (ATT) is most determined by factor b5 (0.872 value) i.e. success in professional career, and by factor b3 ( 0.867 value) which represents promising career prospects. The least important (yet still significant) influence was detected with factor b2, i.e. gaining deeper knowledge and information in a particular field. From the three reference groups that define the "subjective norm" variable (SN) the greatest influenced was measured with group s2 - closest friends and the least influential is group s3 - classmates. The latent variable "perceived behavioural control (PBC) is most determined by factor c3, i.e. the ability to identify own interests, needs and wishes. The variable c1 (lack of information) only achieves 0.495 and therefore does not meet the requirements of the proposed model.

Relationships between individual latent variables that are presumed by the theory of planned behaviour are statistically significant as shown in Tab. $2(\mathrm{P}<0.05)$.

Tab. 2 - Covariance of latent variables - students Faculty of Economics. Source: own processing.

\begin{tabular}{|c|c|c|c|c|c|c|}
\hline \multicolumn{3}{|c|}{ Covariance } & Estimate & S.E. & C.R. & $\mathbf{P}$ \\
\hline ATT & $\leftrightarrow$ & $\mathrm{SN}$ & 15,667 & 4,494 & 3,487 & $* * *$ \\
\hline $\mathrm{SN}$ & $\leftrightarrow$ & PBC & 6,718 & 2,553 & 2,631 & 0,009 \\
\hline ATT & $\leftrightarrow$ & $\mathrm{PBC}$ & 9,639 & 4,413 & 2,184 & 0,029 \\
\hline
\end{tabular}

Construction validity of individual latent variables may be assessed by Cronbach's Alpha indicator with its recommended value should be larger than 0.7 (Hair et al., 2010). Table 3 shows these 
values for three latent variables used in the model and it implicates that the reliability of all latent variables is sufficient.

Tab. 3 - Cronbach's Alpha for latent variables - students of the Faculty of Economics. Source: own processing.

\begin{tabular}{|l|c|}
\hline Latent variables & Cronbach's Alpha \\
\hline attitudes toward the behaviour (ATT) & 0.90 \\
\hline subjective norm (SN) & 0.76 \\
\hline perceived behavioural control (PBC) & 0.71 \\
\hline
\end{tabular}

\subsection{Factors influencing the choice of technical type of university}

As in the previous case, the following figure shows the measurement model for latent variables including the values of standardized regression coefficients.

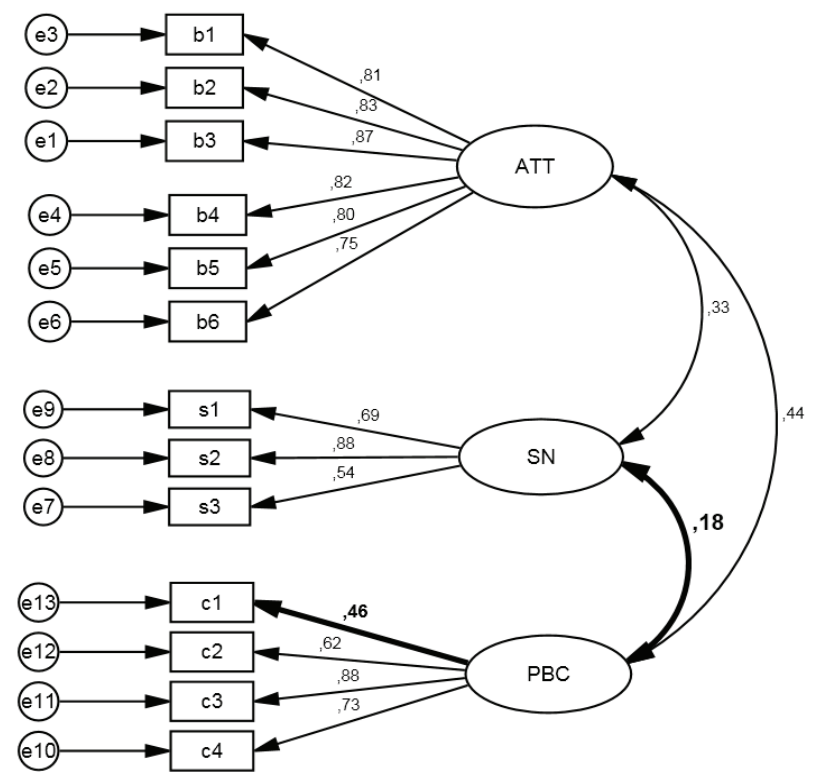

Fig. 3 - Regression coefficients of measurement model - students of the Faculty of Mechanical Engineering. Source: own processing.

Contrary to the measurement model where the factors are evaluated by Faculty of Economics students, in case of Faculty of Mechanical Engineering the relationship between the subjective norm and perceived behavioural control factors is not statistically significant (see Table 4). That can be caused by low value of standardized regression coefficient for the c1 variable (see Figure 3 - highlighted). 
Tab. 4 - Covariance of latent variables - students of the Faculty of Mechanical Engineering. Source: own processing.

\begin{tabular}{|c|c|c|c|c|c|c|}
\hline \multicolumn{2}{|c|}{ Covariances } & Estimate & S.E. & C.R. & P \\
\hline ATT & $\leftrightarrow$ & SN & 22,463 & 10,720 & 2,095 & 0,036 \\
\hline SN & $\leftrightarrow$ & PBC & 7,047 & 5,634 & 1,251 & $\mathbf{0 , 2 1 1}$ \\
\hline ATT & $\leftrightarrow$ & PBC & 39,793 & 13,872 & 2,869 & 0,004 \\
\hline
\end{tabular}

Values of Cronbach's Alpha are again listed in the following table, all comply with the requirement, i.e. are bigger than 0.7 .

Tab. 5 - Cronbach's Alpha for latent variables - students of the Faculty of Mechanical Engineering. Source: own processing.

\begin{tabular}{|l|c|}
\hline Latent variables & Cronbach's Alpha \\
\hline attitudes toward the behaviour (ATT) & 0.92 \\
\hline subjective norm (SN) & 0.75 \\
\hline perceived behavioural control (PBC) & 0.75 \\
\hline
\end{tabular}

\section{DISCUSSION}

It can be stated that the values of standardized regression coefficients expressing the influence of different factors when choosing university are similar whether it is economic or technical type of university. This type of decision-making process is therefore not affected by the type of chosen university.

Within the evaluation of attitudes towards behaviour (latent variable ATT) are the proposed observed variables more determining with students applying for technical faculty which is confirmed by higher value of Cronbach's Alpha. Compared to the students of economical faculty, these students considered the factor of gaining deeper knowledge and information in a particular field more significant. It is therefore possible to state that students of the technical faculty were more motivated by their interest in the chosen field. On the other hand the only factor that proved to be more decisive for the students of the economical faculty was the success in professional career factor.

When analyzing the influence of reference groups on the of university choice (latent variable $\mathrm{SN}$ ) significant difference was found regarding the influence of closest friend. For students of both types of faculties they represent the most determining group of the "significant others", but this factor determined the subjective norm more in case of students of economical faculty.

Also the analysis of perceived behavioural control (latent variable PBC) shows similar results. In both measurement models the factor representing the lack of information during the decisionmaking process was not found as very appropriate. The lack of information is not a barrier when choosing university. Major difference within the type of faculty was noted with the personal skills, abilities and talents factor where the value of standardized regression coefficient is rather 
on the edge of acceptability regarding the decision-making model concerning the students of economy, whereas in the decision-making model of technical faculty students it is much higher. Therefore it is possible to state that in case of students with technical focus personal attributes can be perceived as more dominant limitation and can have a great influence when choosing university.

The analysis was limited by the fact that two different-sized groups of respondents were chosen for comparison. Another problem also consists in the low prestige of the research. Also backwards questioning about the decision-making process that the respondents went through in the past, may present problems in terms of the relevance of data. For this reason only the first year students were questioned.

Within the future research it would be useful to find out to what extend do the stated results differ or correspond for the groups of students from the faculty with the same specialization only in the conditions of different university, eventually how the given factors influence choices of students from different faculties (e.g. humanities or natural sciences). The research could be carried out among students who are in the process of career decision-making or more precisely are choosing the university at that very moment - such act would prevent the mistake resulting from the description of past behaviour.

\section{CONCLUSION}

In this paper, the theory of planned behaviour on process of decision-making regarding the choice of university was applied. Measurement model capturing the relationships between observed variables towards three latent variables, in particular attitudes towards behaviour (the choice of university), subjective norm and perceived behavioural control was examined by the means of structural equation modelling. The measurement model was analyzed and compared separately for students of economical faculty and separately for the students of technical one.

Standardized regression coefficients proved the relationship of all proposed observed variables to the corresponding latent variable except for one case - the lack of information during the decision-making process factor. Values of standardized regression coefficients of other factors are often similar for both types of schools; significant differences were reflected in the criteria related to motivation when choosing university where the students of technical faculty show greater interest in chosen field whilst students of economical faculty are more focused on promising career prospect and consequent succeeding in their future career. At the same time the personal skills, abilities and talents seems to be significant barrier in the decision-making process in case of the technical faculty students.

\section{References}

1. Ajzen, I. (2002). Constructing a TpB Questionnaire: Conceptual and Methodological Considerations. Retrieved from: http://people.umass.edu/aizen/pdf/tpb.questionnaire.pdf

2. Ajzen, I. (2008). Consumer Attitudes and Behavior. In: C. P. Haugtvedt, P. M. Herr \& F. R. Kardes (Eds.). Handbook of Consumer Psychology (525-548). New York: Lawrence Erlbaum Associates. 
3. Ajzen, I. (2012). The Theory of Planned Behavior. In P. A. M.Lange, A. W. Kruglanski \& E. T. Higgins (Eds.). Handbook of Theories of Social Psychology (438-459). London: Sage.

4. Arnold, J. et al. (2006). How well can the theory of planned behavior account for occupational intentions? Journal of Vocational Behavior, 69(3), 374-390. http://dx.doi. org/10.1016/j.jvb.2006.07.006

5. Galotti, K. M., Ciner, E., Altenbaumer, H. E., Geerts. H. J., Rupp, A., \& Woulfe, J. (2006). Decision-Making Styles in a Real-Life Decision: Choosing a College Major. Personality and Individual Differences, 41(4), 629-639. http://dx.doi.org/10.1016/j.paid.2006.03.003

6. Gati, I. \& Asher, I. (2001). The PIC model for career decision making: Prescreening, in-depth exploration, and choice. In T. L. Leong \& A. Barak (Eds.). Contemporary models in vocational psychology: A volume in honor of Samuel H. Osipow (6-54). New Jersey: Lawrence Erlbaum.

7. Gati, I., Landman, S., Davidovitch, S., Asulin-Peretz, L., \& Gadassi, R. (2010). From Career Decision-making Styles to Career Decision-Making Profiles: A Multidimensional Approach. Journal of Vocational Behavior, 76(2), 277-291. http://dx.doi.org/10.1016/ j.jvb.2009.11.001

8. Gati, I. \& Saka, N. (2001). High School Students' Career-Related Decision-Making Difficulties. Journal of Counseling \& Development, 79(3), 331-340. http://dx.doi.org/10.1002/ j.1556-6676.2001.tb01978.x

9. Gati, I. \& Tal, S. (2008). Decision-making models and career guidance. In J. A. Athanasou \& R. Van Esbroeck (Eds.). International Handbook of Career Guidance (157-185). Sydney: Springer.

10. Germeijs, V., Luyckx, K., Notelaers, Gl, Goossens, L., \& Verschueren, K. (2012). Choosing a Major in Higher Education: Profiles of Students' Decision-Making Process. Contemporary Educational Psychology, 27(3), 229-239. http://dx.doi.org/10.1016/j.cedpsych.2011.12.002

11. Hair, J. et al. (2010). Multivariate Data Analysis. USA, New Jersey: Prentice Hall.

12. Nachtigall, Ch., Kroehne, U., Funke, F., \& Steyer, R. (2003). (Why) Should We Use SEM? Pros and Cons of Structural Equation Modelling. Methods of Psychological Research Online, 8(2), 1-22.

13. Pappas, T. S., \& Kounenou, K. (2011). Career Decision Making of Greek Post Secondary Vocational Students: the Impact of Parents and Career Decision Making Selfefficacy. Procedia Social and Behavioral Sciences, 15, 3410-3414. http://dx.doi.org/10.1016/ j.sbspro.2011.04.310

14. Št’astnová, P. \& Drahoňovská, P. (2012). Jak žáci zákialadnich a středních škol vybírají svou dalši vədèlávaci nebo pracovni kariéru. Praha: Národní ústav pro vzdělávání, školské poradenské zařízení a zařízení pro další vzdělávání pedagogických pracovníků.

15. Urbánek, T. (2000). Strukturálni modelování v psychologii. Brno: Psychologický ústav AV ČR a Nakladatelství Pavel Křepela.

\section{Contact information}

Ing. Tereza Navrátilová

$V \grave{S} B$ - Technical University of Ostrava, Faculty of Economics

Sokolská trída 33, 70121 Ostrava, Czech Republic

E-mail:tereza.navratilova@vsb.cz. 